\title{
La fotografía: de la imagen fiel de la realidad, a la imagen transdimensional
}

\author{
Carolina Buenrostro Pérez
}

\section{Resumen}

En este artículo se aborda cómo la imagen fotográfica, reconocida oficialmente en el año 1839 en pleno auge del conocimiento científico, pasó de ser concebida como un medio de registro fiel de la realidad, a una imagen compleja que guarda múltiples dimensiones; y que responde a condiciones de producción, circulación y recepción determinadas por la ideología y el poder.

Palabras clave: imagen fotográfica, complejidad, transdisciplina.

\section{Photography: from the falthful image of reality,}

\section{TO THE TRANS-DIMENSIONAL IMAGE}

\begin{abstract}
This article deals with how the photographic image, officially recognized in the year 1839 at the peak of scientific knowledge, went from being conceived as a means of faithful recording of reality, to a complex image that holds multiple dimensions; and that responds to conditions of production, circulation and reception determined by ideology and power.
\end{abstract}

Key words: photographic image, complexity, transdiscipline.

\section{Carolina Buenrostro Pérez}

carolabupe75@hotmail.com

Estudiante de doctorado en Antropología Social en la Escuela Nacional de Antropología e Historia en México, en la línea de investigación de Análisis del discurso y Semiótica de la cultura con el proyecto: Feminicidio. La reconstrucción transdimensional de la memoria en las prácticas estéticas-artísticas de resistencia política. Sus principales líneas de investigación son el patrimonio cultural inmaterial; así como la semiótica visual y el análisis del discurso en las prácticas estéticas-artísticas atravesadas por la violencia (fotográfica y video). Cursó el diplomado de Fotografía en el Centro Morelense de las Artes y el diplomado en Fotografía Creativa en Galería Punctum. Ha colaborado en distintos proyectos dirigidos a la salvaguardia de patrimonio cultural inmaterial como el Archivo de la Palabra del Instituto Nacional de Antropología e Historia en México; el Congreso Internacional sobre Experiencias en la Salvaguardia del PCI y la Catedra UNESCO sobre patrimonio cultural inmaterial y diversidad cultural de la Universidad Nacional Autónoma de México. Ha participado en congresos nacionales e internacionales y cuenta con publicaciones en temas de patrimonio inmaterial. Es miembro del Comité Académico del Congreso Internacional sobre Experiencias en la Salvaguardia del PCl, y miembro de la Asociación Latinoamericana de Estudios del Discurso (ALED). 
1. Decimos oficial porque desde mucho tiempo atrás se realizaron investigaciones sobre el tema, que fueron aportando conocimientos a este acontecimiento sucedido en 1839.

Imagen 1.

Ruinas de San Juan Teotihucán, México, Autor desconocido

Imagen tomada de: Biblioteca UDLAP
Un conocimiento no es el espejo de las cosas o del mundo exterior. Todas las percepciones son a la vez traducciones y reconstrucciones cerebrales, a partir de estímulos o signos captados y codificados por los sentidos; de ahí, es bien sabido, los innumerables errores de percepción que sin embargo nos llegan de nuestro sentido más fiable, el de la visión. Al error de percepción se agrega el error intelectual.

Morin, 1999: 5
El surgimiento oficial ${ }^{1}$ de la fotografía sucedió en 1839, cuando en la Academia de Ciencias de Francia Louis Daguerre presenta el daguerrotipo, procedimiento fotográfico por medio del cual se logra fijar la imagen en un soporte que puede perdurar en el tiempo. Esto fue en el siglo XIX cuando está en pleno auge el positivismo, un pensamiento filosófico que afirma que el único conocimiento verdadero es el científico; por lo tanto, se buscan certezas, orden y organización, a través de un método que puede ser verificado. Este pensamiento establece que sólo el conocimiento científico podría llevar a la humanidad al progreso y deja fuera de 'la verdad' a todas las demás formas de conocimiento y producción de conocimiento.

Si bien sabemos que la fotografía está ligada a un desarrollo científico, ya que utiliza a las ciencias como la química, la óptica, y ahora a la informática, para su mejora y desarrollo; este hecho también implicó que en ese momento, y aún mucho tiempo después, se le haya otorgado el atributo de ser el medio por el cual se retrataba fielmente a la realidad. De esta manera, las imágenes capturadas por la cámara fotográfica, se convirtieron en las ilustraciones perfectas que acompañaban algunos textos, como los periodísticos, los trabajos arqueológicos y los antropológicos, por ejemplo. (Ver imagen 1)

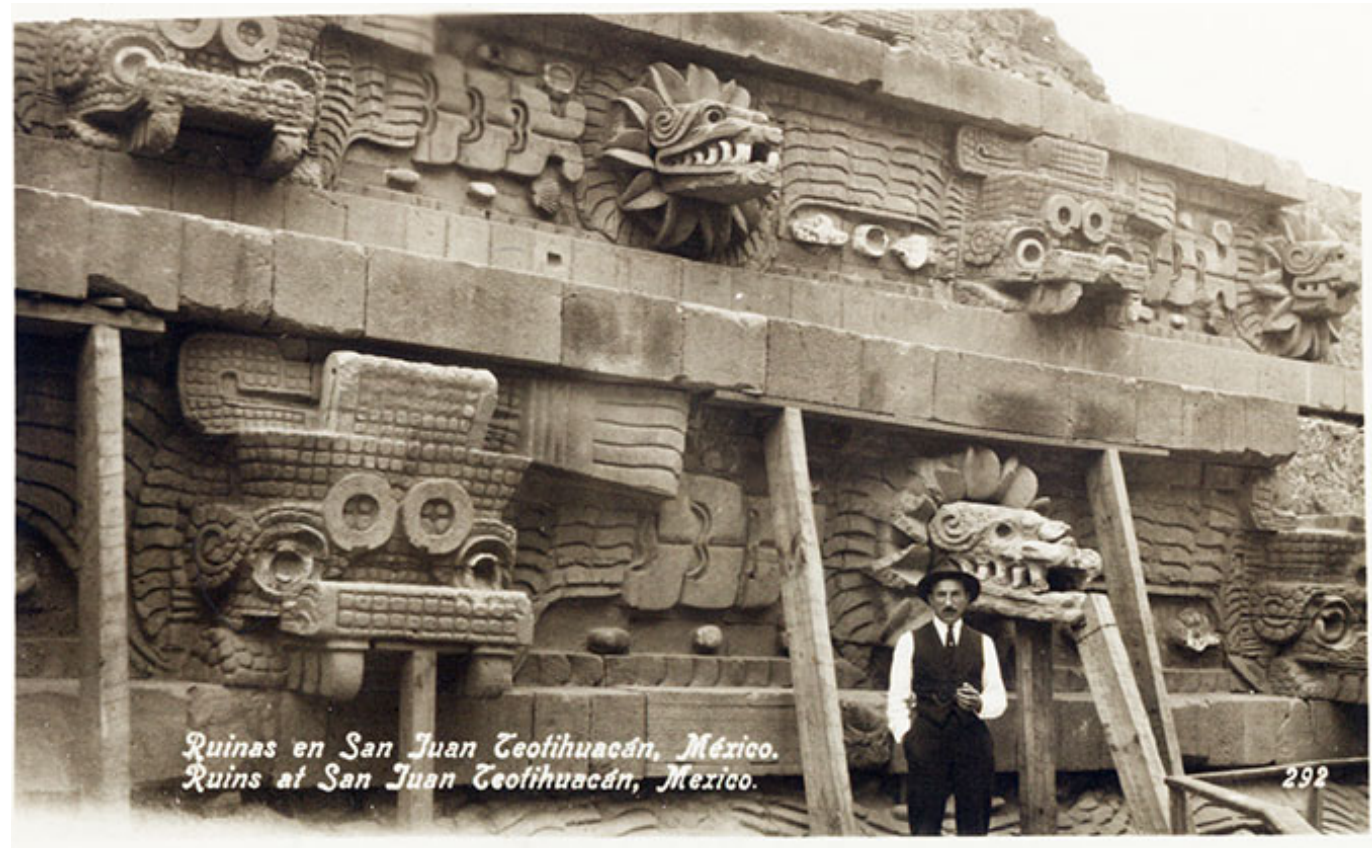


En aquel momento se creía que la fotografía no podía mentir, porque lo que veían en la realidad era tal cual lo que se mostraba después en la imagen impresa. Sin embargo, ahora sabemos que esa idea no es del todo cierta, ya que, desde las primeras imágenes que se realizaron podemos percatarnos que los fotógrafos del siglo XIX y posteriores producían imágenes con una intención estético-artística. Podemos corroborar esto al ver las fotografías que se inspiraron en algunos géneros de la pintura, como el retrato, la naturaleza muerta o el paisaje. Esto quiere decir que su uso no fue solamente el de una ilustración que acompañara investigaciones científicas. (Ver imagen 2)

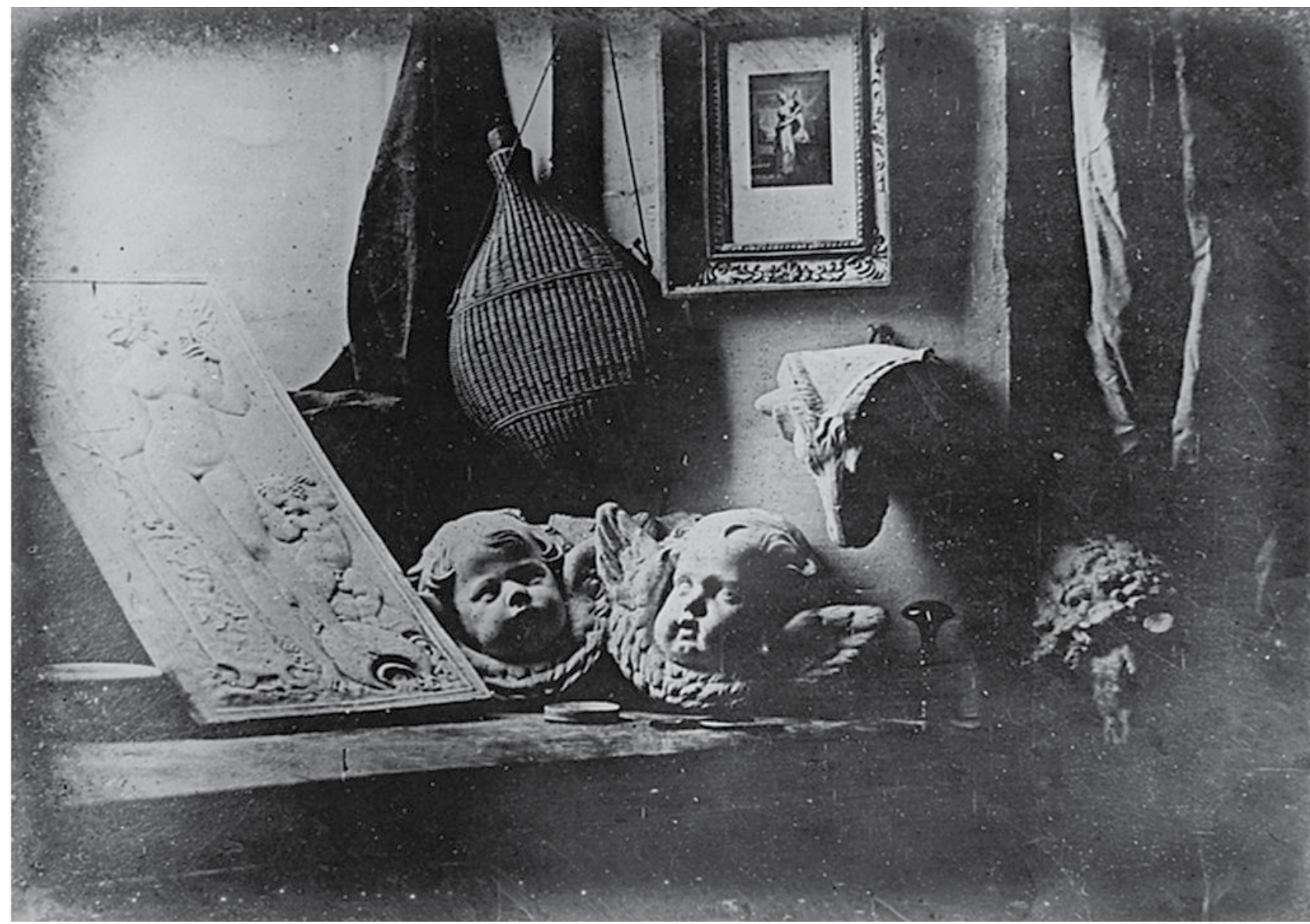

Imagen 2.

L'Atelier de l'artiste (el taller del artista), Louis Daguerre, 1837.

Imagen tomada de: Wikipedia
Más tarde, con la producción a gran escala de cámaras portátiles y la proliferación de lugares donde se podían imprimir los rollos fotográficos (sin que fuera necesario tener todos los conocimientos de técnicas de revelado que conocían sólo los fotógrafos profesionales), la fotografía adquirió un uso recreativo; se convirtió en el medio por el cual las familias (que tenían posibilidad de comprar este aparato) podían guardar sus recuerdos de viajes, fiestas y ceremonias. Asimismo, el fotoperiodismo se benefició de estos modernos aparatos, que pueden ser fácilmente transportados a los lugares donde se encuentran las noticias. (Ver imagen 3). 
Imagen 3.

Anuncio cámaras fotográficas, 1913, George Eastman

Museum

Imagen tomada de:

Eastman.
Actualmente, en pleno siglo $X X I$, el uso de la cámara fotográfica se ha extendido de manera sorprendente, las nuevas tecnologías han permitido que los dispositivos que sirven para realizar imágenes se encuentren integrados a teléfonos portátiles, tabletas digitales o computadoras personales; haciendo más accesible que cualquier persona pueda realizar una fotografía. Pero no sólo ha evolucionado la tecnología de los dispositivos fotográficos, la idea de que la fotografía es un retrato fiel de la realidad se ha ido desvaneciendo con el paso del tiempo; no se está afirmando que la fotografía mienta (aunque sabemos que la imagen puede manipularse y pueden producirse imágenes con esa intención), lo que se quiere plantear en este texto, es que la fotografía no es solamente el resultado mecánico de disparar una cámara, sino el resultado de una práctica de sujetos transdimensionales.

Este cambio fue posible porque surgieron nuevas corrientes de pensamiento como la complejidad y la transdisciplina, que ubican a los sujetos en otras realidades que la ciencia simplista no ha querido reconocer. Mientras que la ciencia simplista apuesta a una división por disciplinas, en donde la hiper-especialización es la forma de conocimiento de la sociedad contemporánea, las ciencias de la complejidad y la transdisciplina apuestan por superar y transgredir las fronteras establecidas entre las disciplinas (Nicolescu, 1996).

Estas nuevas corrientes también plantean que existe un continuum entre la ciencia y la naturaleza, reconocen el azar, la desorganización y la auto-organización; así como también se reconoce la existencia de emociones en los procesos de aprendizaje o de creación de conocimiento de los sujetos. Insisten además en que hay otras formas de conocimiento heredados por culturas ancestrales (que en otros momentos fueron tachados de supersticiones y subdesarrollo); así como que otras manifestaciones del hombre pueden crear conocimiento, como el arte, y que existe un continuum ciencia-arte. 
2. Complexus significa lo que está tejido junto; en efecto, hay complejidad cuando son inseparables los elementos diferentes que constituyen un todo (como el económico, el político, el sociológico, el sicológico, el afectivo, el mitológico) y que existe un tejido interdependiente, interactivo e interretroactivo entre el objeto de conocimiento y su contexto, las partes y el todo, el todo y las partes, las partes entre ellas. (Morin,1999: 17).

3. Para mayor información de la organización visitar su página: http://www.macma.org.ar/

Imagen 4 y 5.

Imágenes que hablan sobre la censura de los senos desnudos de la mujer en redes sociales.

(Da clic en las imágenes para reproducir el video)

Imagen 4 tomada de: Índice.

Imagen 5 tomada de: El Diario vasco
Con base en estos planteamientos, el fotógrafo, que en siglos pasados se consideraba como un sujeto que no interfería con la realidad, ahora se presenta como un homo complexus; es decir, un ser atravesado por distintas dimensiones: social, política, histórica, económica, estética y emocional, por mencionar sólo algunas. A este cúmulo de dimensiones se le denomina transdimensionalidad. Esto quiere decir que cuando alguien produce una fotografía, no la realiza desde su dimensión individual solamente, sino que existen otras dimensiones que inciden de manera directa en las imágenes que produce.

Estas dimensiones siempre son colectivas, es decir, el sujeto las aprende e interioriza porque vive en sociedad. Además no están separadas, se producen y reproducen al mismo tiempo, es decir son complejas², recursivas. Con esto queremos decir que vamos y venimos de una a otra dimensión, en menor o mayor grado; somos sujetos pensantes, históricos, culturales, al mismo tiempo que emotivos, económicos y políticos, sin que alguna de estas dimensiones sea menos o mejor que la otra. Ser sujetos complejos, significa, entre otras cosas, que no estamos solos en el mundo, que vivimos en una sociedad y cultura, que existe una gran variedad de formas de pensar, sentir y habitar el mundo, y que estas condiciones distinguen la forma en que retratamos a través de un aparato fotográfico.

Esta transdimensionalidad del sujeto debe llevarnos a pensar que existen factores sociales, políticos, culturales, etcétera, que determinan la producción, circulación y recepción de la imagen. Siendo el poder y la ideología, los mecanismos que limitan esta producción, circulación y recepción. Pongamos un ejemplo. Las imágenes 4 y 5 pertenecen a un video que lanzó MACMA (Movimiento Ayuda Cáncer de Mama), ${ }^{3}$ como parte de una campaña para promover la detección del cáncer de mamá.

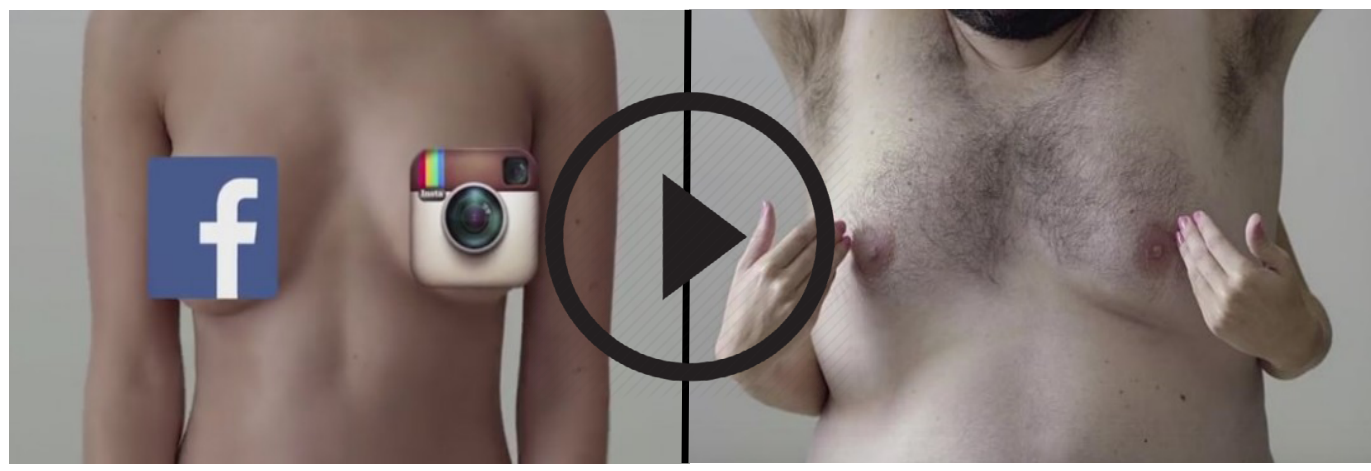

Como podemos observar, la imagen 4 muestra a una mujer de frente, desnuda y los íconos de Facebook e Instagram que cubren sus pezones. Esta campaña denuncia la censura que hacen las redes sociales de las imágenes de los senos desnudos de las mujeres, aun cuando su fin sea el de enseñar al público cómo prevenir los riesgos del cáncer de mama mediante la autoexploración. Es por eso que recurren a los senos de un hombre, que no son censurados en redes sociales, para mostrar cómo debe realizarse una autoexploración mamaria. 


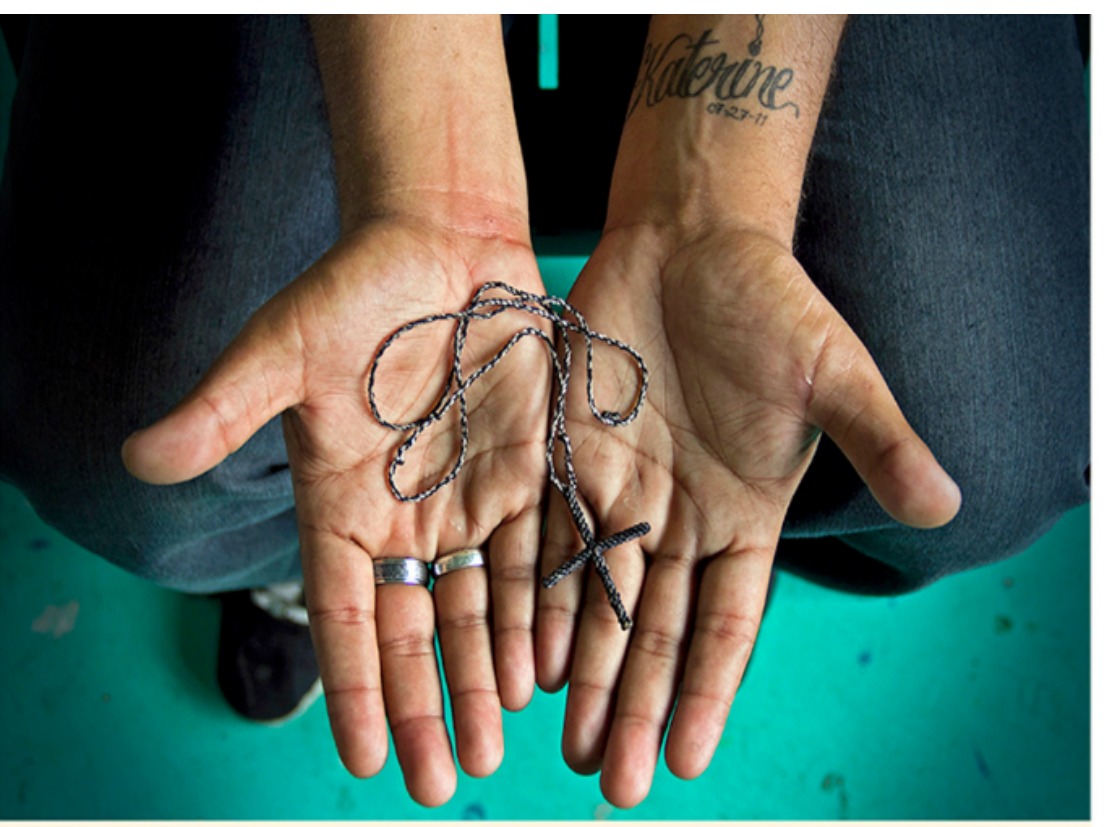

Estas imágenes son evidencia del funcionamiento de la ideología y del poder, que determinan como se producen, circulan y se reciben las fotografías. En este ejemplo podemos observar cómo pueden producirse imágenes que escapen a la censura de las redes sociales; que son las que determinan cuales imágenes son aptas o no para el público que participa en estas redes, censurándolas y excluyéndolas. Esta campaña lanzada por MACMA cuestiona por qué es permitido ver el pecho de un hombre desnudo, y no el de una mujer desnuda en redes sociales. Además es muy directa y debemos considerar por lo tanto quién la realiza; se trata de MACMA una organización que busca que las mujeres tengan más información sobre su salud; que insiste en terminar con el tabú del cáncer que existe en torno a esta enfermedad; y que quiere llegar a la mayor cantidad de público posible,

Albergue: "La 72". Tenosique, Tabasco. Nombre: Herson Alberto $\mathrm{Hdz}$. Rivera

Edad: 24 años Estado civil: Destino: Panorama City, California

Origen: San Miguel, Bl Salvador Ocupacion: Trabajos diversos Motivo de migracion: Vivi6 ya siete años en EU. Deportado pero intenta cruzar de nuevo. Teme volver al Salvador por represalias de la Mara.

Contratiempos durante el trayecto: Fue asaltado en las vías en Tierra Blanca, Ver. por eso se atreve a desafiar a estas compañías poderosas mediante una campaña creativa.

Hay otros ejemplos de fotógrafos que realizan imágenes hechas para denunciar algún problema social, que se producen, no desde
Imagen 6.

Perteneciente a la serie fotográfica Reliquias (2012), de Olivia Vivanco. Copyrigth(c) 2015 Olivia-Vivanco-Torres aquella fotografía que procuraba retratar la realidad fielmente, sino que aprovechan al máximo las dimensiones estético-artística, emotiva, para conjuntarlas con otras dimensiones sociales, políticas, históricas que los atraviesan. Por ejemplo, el trabajo fotográfico "Reliquias" (2012), de Olivia Vivanco tiene como objetivo mostrar las condiciones de precariedad económica e inseguridad en la que viajan los migrantes centroamericanos para llegar a los Estados Unidos, y a los que retrata en su paso por el albergue "La 72", en Tenosique, Tabasco. Es un trabajo que conjuga la poética y las emociones, con una realidad de desigualdad social y económica en un contexto de violencia. (Ver imagen 6).

Este trabajo no busca la denuncia directa de las precarias condiciones y violencia en que viajan estos migrantes centroamericanos; más bien recurre a las emociones que puede despertar en el espectador que observa en las fotografías la importancia que le dan los migrantes a
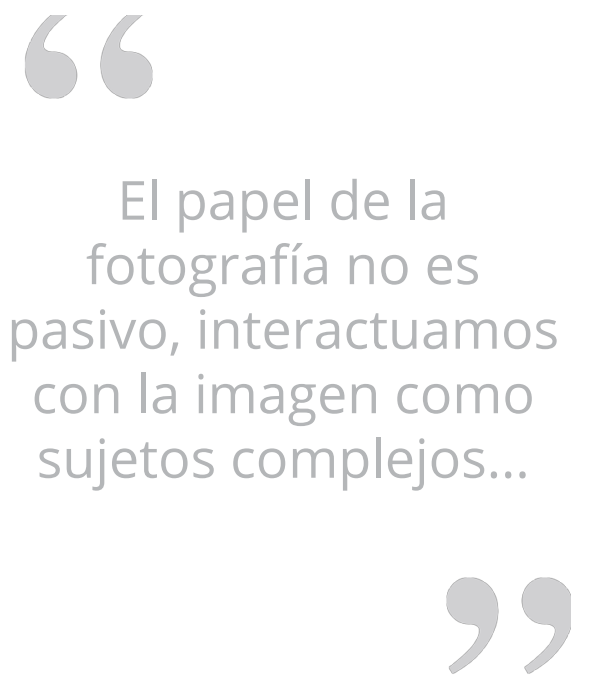
los pocos objetos que llevan consigo; y que son el único recuerdo de su país y de sus seres queridos, la dimensión emotiva es la donde se centra la fuerza de este trabajo fotográfico. ¿Por qué no se les ve la cara a estos migrantes? ¿Por qué se ocultan si retratar su rostro sería la mejor prueba de que ese sujeto existe? ¿No sería un retrato fiel de la realidad de la migración fotografiar su rostro? ¿Por qué se hace hincapié en la ficha que contiene los datos de estos migrantes? Podemos lanzar varias hipótesis que contesten a estas preguntas, sólo dejo en la mente del lector que estos sujetos fueron fotografiados en "La 72" en Tenosique, Tabasco, un lugar que fue nombrado así para recordar a 72 migrantes secuestrados y asesinados por el crimen organizado, cuyos cuerpos fueron encontrados en el año 2010, en el Municipio de San Fernando, Tamaulipas.

Hemos visto cómo las imágenes fotográficas nos revelan que existen múltiples dimensiones en la cultura humana, y que tienen diferentes funciones como ser memoria y comunicar un mensaje Lotman (1996); que transmiten esta información de diferentes formas, ya sea produciendo imágenes artísticas-estéticas que apelen a las emociones que pueden despertar en el público receptor, o produciendo fotografías más cercanas al fotoperiodismo, por poner sólo algunos ejemplos. Asimismo nos permiten conocer cómo piensan y ven los sujetos que producen estas fotografías al mundo, considerando que éstos están atravesados por múltiples dimensiones y que la ideología y el poder juegan un papel importante en su producción, circulación y recepción.

El papel de la fotografía no es pasivo, interactuamos con la imagen como sujetos complejos, nos alejamos cada vez más de considerarla un mero registro fiel de la realidad a la que pretendía constreñirla el pensamiento hegemónico del siglo XIX. Estas nuevas posiciones existen no sólo porque hayan pasado casi dos siglos de su nacimiento oficial, sino porque estamos descubriendo y aprendiendo otras formas de conocer el mundo que nos llevan a otros rumbos muy lejanos de la ciencia positivista, que desconoce todas las problemáticas que tratamos.

\section{Referencias}

* Bajtín, M. (1989). Teoría y estética de la novela. Madrid, España: Taurus.

* Carrizo, L., et al. (2004). Gestión de las Transformaciones Sociales MOST Documento de debate - no. 70. Transdisciplinariedad y Complejidad en el Análisis Social. Paris, Francia: UNESCO.

* Haidar, J. (2006). Debate CEU-Rectoría. Torbellino pasional de los argumentos. Ciudad de México, México: UNAM.

- Lotman, I. (1982). La estructura del texto artístico. Madrid, España: Libro de bolsillo Itsmo.

* Lotman, I. (1996). La Semioesfera I. Semiótica de la cultura y el texto. Madrid, España: Ediciones Catedra. 
* Morin, E. (1977). El Método I. Madrid, España: Editorial Cátedra.

* Morin, E. (1997). Introducción al pensamiento complejo. Barcelona, España: Editorial Gedisa.

- Morin, E. (1999). Los siete saberes necesarios para la educación del futuro. Paris, Francia: UNESCO.

- Nicolescu, B. (1996). La transdisciplinariedad. Manifiesto. Recuperado de http:// www.ceuarkos.com/manifiesto.pdf.

* Varios autores (2002) Manual de iniciación pedagógica al pensamiento complejo. Paris, Francia: UNESCO.

* Varios autores (1994). Carta de Fundación de la Transdisciplinariedad. Portugal: O Congreso Internacional de la Transdisciplina. Recuperado de http://www.filosofia. org/cod/c1994tra.htm.

\section{Cómo citar este artículo}

* Buenrostro Pérez, C. (2018). La fotografía: de la imagen fiel de la realidad, a la imagen transdimensional. Revista Digital Universitaria (RDU). Vol. 19, núm. 2 marzoabril. DOI: http://doi.org/10.22201/codeic.16076079e.2018.v19n2.a4 